\title{
FENTANYL DOSE AND OUTCOME IN PRETERM INFANTS UNDERGOING PDA CLOSURE
}

José L. Martinez, MD*,Annie Janvier, MD, FRCPC** ,Josée Lavoie, MD, FRCPC* . Departments of Anesthesiology* and Neonatology **, Montreal Children's Hospital, McGill University Health Centre, 2300 Tupper, Montreal, Quebec, H3H 1P3

\section{INTRODUCTION}

Patent Ductus Arteriosus (PDA) is currently the most common congenital heart disease presenting in preterm infants. As a result of the increased survival of premature infants, surgical closure of PDA is performed more frequently. The aim of this study was to assess the impact of the anesthetic technique on outcome.

\section{METHODS}

After obtaining IRB approval, a retrospective cohort study was conducted using anesthetic records and medical charts of infants who underwent surgical closure of PDA between September 2001 and June 2003. Patient demographics, preoperative status, anesthetic technique and postoperative course were evaluated. The reviewer was blinded to outcome. Unstable Postoperative Respiratory Course (UPRC) was defined as respiratory instability requiring an increase in $\mathrm{FiO}_{2}>25$, or an increase in pulmonary inspiratory pressure $>3 \mathrm{~cm} \mathrm{H}_{2} \mathrm{O}$ compared to preoperative baseline, or requirement for manual ventilation with $100 \%$ oxygen. The total fentanyl dose used for general anesthesia was compared against UPRC. Differences were assessed using a T-test.

\section{RESULTS}

Thirty-nine patients underwent surgical closure of PDA during the study period. The mean postconceptual age was $29.5+/-1.8$ weeks and mean weight was $1.031+/-0.287 \mathrm{~kg}$. All patients received intraoperative opioids. The mean dose of fentanyl administered was $18.4+/-16.2 \mathrm{mcg} \cdot \mathrm{kg}^{-1}$. Eight patients presented UPRC. Mean fentanyl doses were $5.3+/-2.6 \mathrm{mcg} \cdot \mathrm{kg}^{-1}$ for patients with UPRC vs. $22.6+/-16.6 \mathrm{mcg} \cdot \mathrm{kg}^{-1}$ for patients without UPRC $(\mathrm{p}=0.004)$. Both groups were similar with regards to demographics and preoperative status. Applying the receiver-operator characteristic curve, a dose of $10.5 \mathrm{mcg} \cdot \mathrm{kg}^{-1}$ of fentanyl was the cut-off value that discriminated and identified patients who experienced UPRC. Patients who presented UPRC all received less than $10.5 \mathrm{mcg} \cdot \mathrm{kg}^{-1}$ of fentanyl.

\section{DISCUSSION}

These findings suggest that a minimum dose of at least $10.5 \mathrm{mcg} \cdot \mathrm{kg}^{-1}$ of fentanyl promotes postoperative respiratory stability in preterm infants undergoing PDA closure. These results are in agreement with previous studies that report decreased stress response ${ }^{1}$ and improved postoperative protein metabolism ${ }^{2}$ with fentanyl doses of 10 and $15 \mathrm{mcg} \cdot \mathrm{kg}^{-1}$ respectively in the same patient population.

\section{REFERENCES}

1. Lancet, January 10, 1987; 1(8524): 62-66

2. Journal of Pediatric Surgery, 35:1277-1281 